\title{
Role of p21 as a determinant of 1,6-Bis[4-(4-amino- 3-hydroxyphenoxy)phenyl] diamantane response in human HCT-116 colon carcinoma cells
}

\author{
JANE-JEN WANG ${ }^{1}$, HUI-FANG HUNG ${ }^{1}$, MIN-LI HUANG ${ }^{1}$, HUI-JU LEE ${ }^{2}$, \\ YAW-TERNG CHERN ${ }^{3}$, YUH-FANG CHANG ${ }^{4}$, CHIN-WEN CHI ${ }^{4,5}$ and YI-CHIUNG HSU ${ }^{6,7,8}$
}

${ }^{1}$ Center of General Education, National Taipei University of Nursing and Health Sciences, Taipei; ${ }^{2}$ Institute of Biomedical Sciences, Academia Sinica, Taipei; ${ }^{3}$ Department of Chemical Engineering, National Taiwan University of Science and Technology, Taipei; ${ }^{4}$ Department of Medical Research and Education, Taipei Veterans General Hospital, Taipei; ${ }^{5}$ Institute of Pharmacology, School of Medicine, National Yang-Ming University, Taipei; ${ }^{6}$ Division of Genomic Medicine, Research Center for Medical Excellence, National Taiwan University, Taipei; ${ }^{7}$ Institute of Statistical Science, Academia Sinica, Taipei; ${ }^{8}$ Department of Horticulture and Biotechnology, Chinese Culture University, 55 Hwa-Gang Road, YangMingShan, Taipei 111, Taiwan, R.O.C.

Received August 18, 2011; Accepted September 26, 2011

DOI: $10.3892 / o r .2011 .1546$

\begin{abstract}
Bis[4-(4-amino-3-hydroxyphenoxy)phenyl] diamantane (DPD) induces growth inhibition in human cancer cells. In our previous study, we discovered that DPD irreversibly inhibits the growth of Colo 205 colon cancer cells at the $\mathrm{G}_{0} / \mathrm{G}_{1}$ phase and induces cell differentiation. However, the detailed mechanism is still unknown. In this study, we examined the functional importance of p21 and p53 in DPD-induced anticancer effects. We used three isogenic cell lines, HCT-116, HCT-116 $\mathrm{p}^{-1-}$ and HCT-116 $\mathrm{p} 21^{--}$, to evaluate the roles of $\mathrm{p} 21$ and 553 in the in vitro anticancer effects of DPD. The in vivo anti-proliferative effect of DPD was demonstrated by HCT-116 and HCT-116 $\mathrm{p}^{-1^{--}}$xenograft models. DPD significantly inhibited the growth as well as increased the number of HCT-116 cells in the $\mathrm{G}_{0} / \mathrm{G}_{1}$ phase, but not in HCT-116 $\mathrm{p} 53^{-/}$and HCT-116 $\mathrm{p} 21^{-1-}$ cells examined by flow cytometry. Additionally, Western blot analysis showed that DPD treatment induced p21, but not p53 protein expression in HCT-116 cells. The p21-associated cell cycle regulated proteins, such as cyclin $\mathrm{D}, \mathrm{CDK} 4$ and $\mathrm{pRb}$ were decreased after DPD treatment in HCT-116 cells. The DPD-increased $\mathrm{G}_{0} / \mathrm{G}_{1}$ phase and induced cell cycle regulated protein expression were not observed in HCT-116 $\mathrm{p} 21^{-/}$and

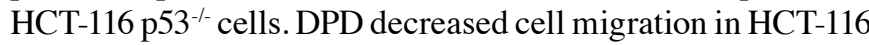

Correspondence to: Dr Yi-Chiung Hsu, Division of Genomic Medicine, Research Center for Medical Excellence, National Taiwan University, Taipei, Taiwan, R.O.C.

E-mail: syic@stat.sinica.edu.tw

Dr Chin-Wen Chi, Department of Medical Research and Education, Taipei Veterans General Hospital, Taipei, Taiwan, R.O.C.

E-mail: cwchi@vghtpe.gov.tw

Key words: colorectal carcinoma, cell cycle, p21, anti-proliferation, anti-migration, diamantane and HCT-116 $\mathrm{p}^{-/-}$but not in HCT-116 p21 ${ }^{-/}$cells. p21 was required for the DPD-induced in vitro anti-colon cancer effect. The in vivo study also showed that DPD significantly inhibited tumor growth through p21 signaling. Our results clearly demonstrate that DPD-induced in vitro and in vivo anticancer effects through the activation of p21 in HCT-116 cells.

\section{Introduction}

Colorectal cancer (CRC) is a major cause of mortality in the world $(1,2)$. Many CRC patients undergo chemotherapy without survival benefit despite significantly improved response rates achieved by multidrug combination therapy. Chemotherapeutic agents such as the topoisomerase I inhibitor irinotecan (CPT-11) and a platinum-based chemotherapy agent oxaliplatin are used as second-line chemotherapeutic agents for patients who have failed to respond to previous 5-FU-based chemotherapy, but the survival remains poor for patients with metastatic colorectal carcinoma (3-5). Although CPT-11 and oxaliplatin have been shown to be highly effective in the treatment of colon cancer, the dosage is limited by toxicities, such as diarrhea and neurotoxicity (6,7). Therefore, developing new anticancer drugs would greatly improve CRC therapy.

Adamantane derivatives possess several attractive pharmacological activities, such as anti-bacterial, anti-fungal, anti-viral and anticancer effects (8-10). In our previous studies, we had characterized the anticancer activities of adamantane and diamantane derivatives using the 60 human cancer cell lines in the NCI Anticancer Drug Screen and evaluated the structure-activity relationship. The diamantane derivative 1,6-Bis[4-(4-amino-3-hydroxyphenoxy)phenyl] diamantane (DPD) exhibited marked anticancer activities on colon cancer (Colo 205), leukemia (HL-60), non-small cell lung cancer (HOP92), ovarian cancer (OVCAR-8) and breast cancer (T-47D) cell lines (11). The anti-proliferative effects and differentiation- 
inducing property of DPD were demonstrated in human colon cancer cells (12). DPD also induced $\mathrm{G}_{1}$ arrest in Colo 205 cells and this effect was irreversible after removal of DPD (11). In addition, we also examined the in vivo therapeutic potential of DPD in Colo 205 cell xenografts. No acute toxicity was observed after an intraperitoneal (i.p.) challenge of mice with DPD once a week (12). Therefore, these results suggest that DPD is a potential anticancer drug for CRC therapy.

The $\mathrm{G}_{1}-\mathrm{S}$ transition of the cell cycle is driven mainly by cyclin-dependent kinase (CDK) that is controlled by the CDK inhibitors, p21 and p27. The activity of the CDK family appears to be increased in some tumor cells in which these natural inhibitors of CDK activity may be absent or mutated (13). Thus, the development of potent CDK inhibitors would represent a novel approach for the inhibition of tumor cell growth. Down-regulation of p21 expression was associated with poor prognosis (14). In colorectal cancer, the induction of p21 occurs mostly in a p53-dependent pathway. p21, as the main CDK inhibitor, may also inhibit the activity of cyclin D1 (14). On the other hand, p21 was required for senescence development of HCT-116 cells following treatment with low concentrations of camptothecin (15). The development of p21 inducers is important in human colon cancer therapy.

In this study, we evaluated the action mechanism in the anti-proliferative effects of DPD in colon carcinoma cell lines. We previously demonstrated that DPD suppresses the growth of colon cancer cells mainly by inducing cell cycle arrest. We further examined the role of p21 and p53 in the cellular response against DPD using wild-type, $\mathrm{p} 21^{-/-}$and $\mathrm{p} 53^{-/-}$isogenic HCT-116 colon carcinoma cells. We demonstrate that DPD dosedependently inhibited cell growth and increased the number of HCT-116 cells, but not of p21/- and p53 ${ }^{-/}$isogenic HCT-116 cells at the $\mathrm{G}_{0} / \mathrm{G}_{1}$ phase. DPD treatment induced $\mathrm{p} 21$ but not $\mathrm{p} 53$ protein expression in HCT-116 cells. A HCT-116 p21 ${ }^{-/}$tumor xenograft experiment further demonstrated that $\mathrm{p} 21$ played an essential role in the DPD anti-tumor growth effect.

\section{Materials and methods}

Cell culture and DPD treatment. Human colon cancer cell lines, HCT-116 (ATCC-CCL-247), HCT-116 p53 ${ }^{-/}$and HCT-116 p21 $1^{-1-}$ were grown in McCoy's 5A medium (Sigma-Aldrich, St. Louis, MO) supplemented with $10 \mu \mathrm{g} / \mathrm{ml}$ Pen-Strep-Ampho-Sol (Biological Industries, Beit Haemeq, Israel), 10\% fetal bovine serum at $37^{\circ} \mathrm{C}$ in a humidified atmosphere containing $5 \%$ $\mathrm{CO}_{2}$. DPD was dissolved in DMSO (Sigma-Aldrich) at a stock concentration of $10 \mathrm{mM}$ and added to culture media at a final concentration of 1-5 $\mu \mathrm{M}$. Cells were seeded at $1.3 \times 10^{6}$ cells/10-cm dish in growth medium containing DPD. The final concentration of DMSO was $0.1 \%$.

Sulforhodamine B (SRB) cell proliferation analysis. Cells seeded at a density of $8 \times 10^{3}$ cells/well in 96 -well plates were treated with various doses of DPD for 48,72 and $96 \mathrm{~h}$. The total biomass of cells was determined by SRB analysis. Briefly, cells were fixed by cold $10 \%$ trichloroacetic acid (TCA) (Sigma-Aldrich) at $4^{\circ} \mathrm{C}$ for $1 \mathrm{~h}$. After washing with tap water and air dried, fixed cells were incubated with $0.1 \%$ SRB (Sigma-Aldrich) dissolved in $1 \%$ acetic acid for $30 \mathrm{~min}$ then rinsed five times with $1 \%$ acetic acid to remove unincorporated dye. The protein-bound dye was then extracted with $10 \mathrm{mM}$ Tris ( $\mathrm{pH} \mathrm{10.5)} \mathrm{and} \mathrm{the} \mathrm{absorbance} \mathrm{at} 510 \mathrm{~nm}$ of this extract was measured by an ELISA reader (Molecular Devices, Sunnyvale, CA).

Cell cycle analysis. The Cycle TEST Plus DNA Reagent kit (Becton-Dickinson, San Jose, CA) was used for DNA staining. After washing the cells twice with buffer solution, the cell concentration was adjusted to $1.0 \times 10^{6} \mathrm{cells} / \mathrm{ml}$ and $0.5 \mathrm{ml}$ of cell suspension was centrifuged at $400 \mathrm{x}$ g for $5 \mathrm{~min}$ at room temperature. The cell pellet was added with $250 \mu \mathrm{l}$ of Solution A (trypsin buffer) and gently mixed. After incubation at room temperature for $10 \mathrm{~min}, 200 \mu \mathrm{l}$ of Solution B (trypsin inhibitor and RNase buffer) was added to each tube, gently mixed and then incubated at room temperature for $10 \mathrm{~min}$. This was followed by the addition of $200 \mu \mathrm{l}$ of Solution C [PI (propidium iodide) staining solution] and incubated for $10 \mathrm{~min}$ in the dark on ice. The sample was filtered through a 50-mm nylon mesh and used for flow cytometric analysis. The red fluorescence (PI) was collected through a 585-nm filter (FL-2) for cell cycle analysis. Data were analyzed using CellQuest and ModFit software on a Macintosh computer.

Western blot analysis. Whole cell lysates were prepared by M-PER (Thermo Scientific, Rockford, IL) supplemented with protease inhibitors cocktail (Calbiochem, La Jolla, CA) and phosphatase inhibitor (Thermo Scientific, Rockford, IL) according to the manufacturer's protocol. Protein lysates were separated on $12 \%$ SDS-polyacrylamide gels and blotted onto nitrocellulose membranes. Primary antibodies including p21 (BD Biosciences PharMingen, San Deigo, CA), p53, cyclin E, cyclin D, CDK2, CDK4, pRb (Santa Cruz Biotechnology Inc., Santa Cruz, CA) and $\beta$-actin (Sigma-Aldrich) were then used to probe these proteins. After incubation at $4^{\circ} \mathrm{C}$ overnight, the membranes were washed with Tris buffer saline Tween-20 buffer and then incubated with horseradish peroxidaseconjugated secondary antibodies (Millipore, MA). Protein visualization was performed using the enhanced chemiluminescence kit (ECL kit, Pierce, Rockford, IL).

Transwell cell migration analysis. HCT-116, HCT-116 p53 $3^{-/}$and HCT-116 p $21^{-/-}$cells were seeded at $3 \times 10^{5}$ cells per $60-\mathrm{mm}$ dish in growth medium. The cells were replenished on the following day with medium containing the vehicle control $\left(0.1 \%\right.$ DMSO) or DPD $(2 \mu \mathrm{M})$ for $48 \mathrm{~h}$. Then, $1 \times 10^{5}$ cells were seeded with $100 \mu 1$ serum-free medium on the top chambers of 24 -well Transwell plates ( $8 \mu \mathrm{m}$ pore size, Corning Costar Biosciences, Acton, MA). Growth medium was added to the bottom chambers as the chemoattractant. After incubation for $24 \mathrm{~h}$, cells on the top surface of Transwell inserts (non-migrated) were removed by cotton-swab. Cells on the bottom surface of the Transwell insert (migrated) were fixed by $4 \%$ formaldehyde and stained with $0.1 \%$ Giemsa solution (Sigma-Aldrich). Photographs were taken using phase-contrast microscropy and images were captured using the AxioVision software (Carl Ziess, Göttingen, Germany).

In vivo anti-proliferative effect of DPD on human colon cancer HCT-116 and HCT-116 p21 $1^{-/}$xenografts. The in vivo experiments were carried out with Institutional Animal Care 
and Use Committee approval (96-174), and met the standards required by the UKCCCR Guidelines (16).

The 5-week-old male BALB/cAnN.Cg-Foxn1nu/CrlNarl nude mice were obtained from the National Laboratory Animal Center of National Applied Research Laboratories (Taipei, Taiwan) and housed in air-filtered cages under sterilized conditions at $25^{\circ} \mathrm{C}$ and light controlled 12-h light and 12-h dark cycles. HCT-116 and HCT-116 p21 ${ }^{-/-}$cells were harvested and resuspended in PBS. Cells were adjusted to $1.5 \times 10^{6}$ cells $/ \mathrm{ml}$ and injected subcutaneously on one side of the flank region of nude mice. Each experimental group included 3-6 tumor-bearing mice. DPD was dissolved in DMSO, and treatment was initiated when the tumor size was 2-4 mm. DPD was administered via i.p. injection twice a week at a dose of $35 \mathrm{mg} / \mathrm{kg}$. The control group received DMSO vehicle. Tumor size and body weight were monitored twice a week. Tumor volume (V) was calculated according to the following formula: $\mathrm{V}\left(\mathrm{mm}^{3}\right)=$ $0.4 \mathrm{AB}^{2}$, where $\mathrm{A}$ and $\mathrm{B}$ are the longest and shortest diameter, respectively (31). Tumor growth index (TGI) $=\mathrm{V}_{\mathrm{n}} / \mathrm{V}_{0}$, where $\mathrm{V}_{\mathrm{n}}$ is the tumor volume of the treated group on day $\mathrm{n}$ and $\mathrm{V}_{0}$ is the initial tumor volume. At the end of the experiment, all mice were sacrificed by $\mathrm{CO}_{2}$ gas

Statistics. All in vitro data are expressed as the mean \pm SD (standard deviation). In vivo animal data are expressed as the mean $\pm \mathrm{SE}$ (standard error). Between-group comparisons were analyzed by ANOVA. $\mathrm{P}<0.05$ is considered to indicate a significant difference.

\section{Results}

Effects of DPD on the growth and cell cycle progression of HCT-116 cells. No obvious effects on cell growth were observed after treatment with $1 \mu \mathrm{M}$ DPD, but 2-5 $\mu \mathrm{M}$ DPD treatment resulted in growth inhibition in HCT-116 cells at 48-96 h (Fig. 1A).

In order to assess the effect of DPD on cell cycle progression, HCT-116 cells were stained by PI and measured by flow cytometry at $48 \mathrm{~h}$ following $2-\mu \mathrm{M}$ DPD drug treatments. Compared to the DMSO control, DPD increased the percentage of $\mathrm{G}_{0} / \mathrm{G}_{1}$ phase (82.87 vs. $44.20 \%$ ) cells and reduced the cells in the $\mathrm{S}(8.46$ vs. $37.17 \%)$ and $\mathrm{G}_{2} \mathrm{M}(8.68$ vs. $18.63 \%)$ phases of the cell cycle in HCT-116 wild-type cells (Fig. 1B).

Cell signaling proteins related to DPD treatment on HCT-116 cells. In a previous experiment, we confirmed that DPD increased the percentage of HCT- 116 cells the $G_{0} / G_{1}$ phase. In order to search for the pathway involved in the DPD increase of the $\mathrm{G}_{0} / \mathrm{G}_{1}$ phase, HCT-116 cells were treated with $2 \mu \mathrm{M}$ DPD for 16,24 and $48 \mathrm{~h}$, and the cells were harvested for Western blotting. We observed the up-regulation of p21, and the downregulation of $\mathrm{pRb}$ and cyclin $\mathrm{D} / \mathrm{CDK} 4$ in the DPD-treated groups (Fig. 2). p53, cyclin E and CDK2 showed no significant differences between the DPD-treated and control groups.

Effects of DPD on the growth of HCT-116, HCT-116 p53\%and HCT-116 $\mathrm{p}^{-1 /}$ cells. To further assess the mechanism of growth inhibition caused by DPD, we used HCT-116, HCT-116 p53 $3^{-/}$and HCT-116 p $21^{-/-}$cells to examine the role of p53 and p21 in DPD-induced effects. We used Western blotting to
A

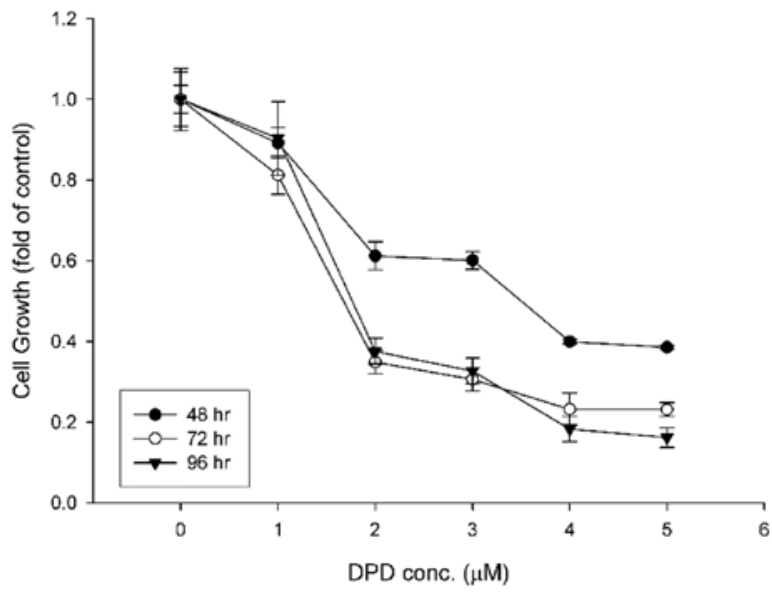

B

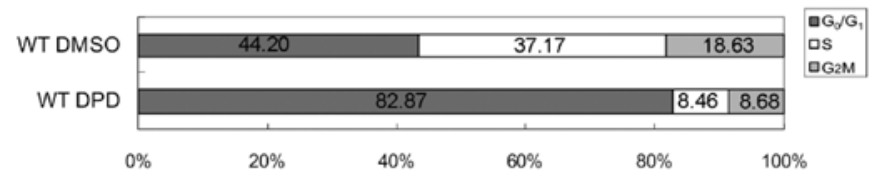

Figure 1. (A) Effects of DPD on the growth of HCT-116 cells. HCT-116 cells were seeded at $8 \times 10^{3}$ cells per well in a 96-well microtiter plate. On the following day the cells were replenished with medium containing $0.1 \%$ DMSO, $1,2,3,4$, or $5 \mu \mathrm{M}$ DPD and incubated for $48-96 \mathrm{~h}$. The cell growth was analyzed by the sulforhodamine (SRB) binding assay. Each determination represents the mean \pm SD absorbance of six replicates. The data are representative of three reproducible independent experiments. (B) Effects of DPD on cell cycle progression of HCT-116. Cells were seeded at a density of $2 \times 10^{5}$ cells/well in 6-well plate and allowed to attach for $24 \mathrm{~h}$. The original culture medium was then replaced with a medium containing DMSO or $2 \mu \mathrm{M}$ DPD. Cells were harvested and processed for cell cycle analysis by flow cytometry after treatment for $48 \mathrm{~h}$. Experiments shown are representative of three independent experiments.

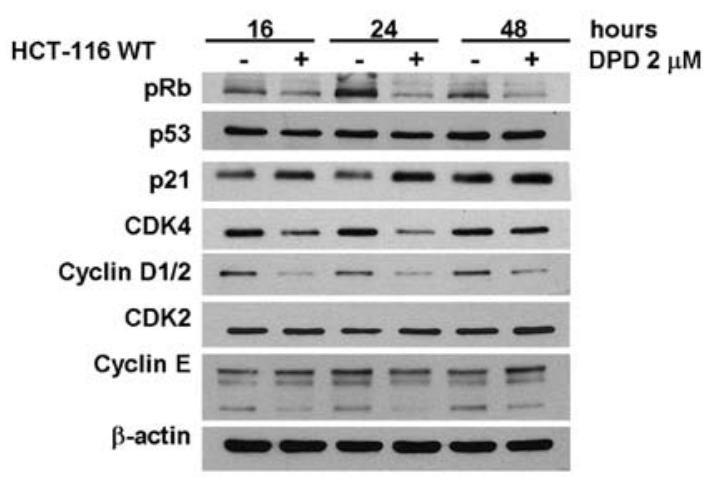

Figure 2. Cell cycle related protein expression in HCT-116 cells after $2 \mu \mathrm{M}$ DPD treatments. Whole cell lysates from HCT-116 cells were used for gel electrophoresis and Western blotting with primary antibodies against $\mathrm{pRb}$, p53, p21, cyclin D1/2, cyclin E, CDK4, CDK2 and $\beta$-actin.

check the p53 and p21 protein expression level in these three cell lines. Our results clearly showed the lack of p53 expression in HCT-116 p53 $3^{-/}$cells, and of p21 expression in HCT-116 p $21^{-/}$ cells (Fig. 3A). As shown in Fig. 3B, 2-5 $\mu \mathrm{M}$ DPD treatment resulted in a 40-70\% cell number reduction of wild-type cells, but had no effect on the growth of HCT-116 $\mathrm{p} 53^{-/-}$or $\mathrm{p} 21^{-/-}$cells. 
A

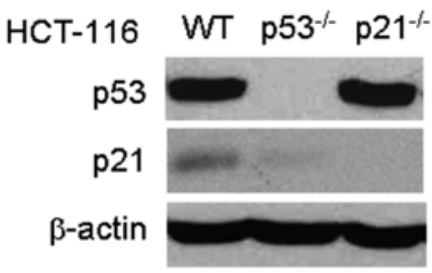

B

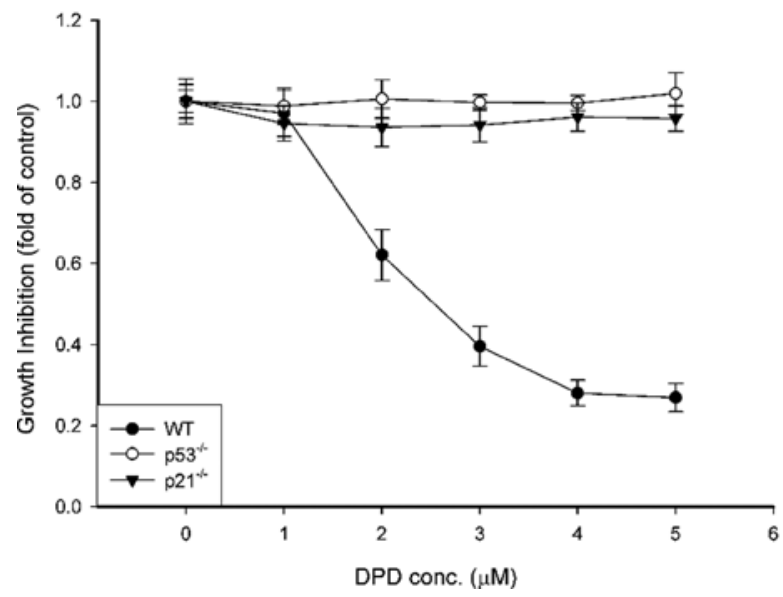

Figure 3. (A) p53 and p21 protein expression in HCT-116 (WT), HCT-116 p53 ${ }^{-/}$and HCT-116 $\mathrm{p}^{-/-}$cells. Whole cell lysates from HCT-116, HCT-116 p53 ${ }^{-/}$and HCT-116 $\mathrm{p} 21^{-/}$cells were used for gel electrophoresis and Western blotting with primary antibodies against $\mathrm{p} 53, \mathrm{p} 21$, and $\beta$-actin. The $\beta$-actin signal was used for normalization. (B) Effects of DPD on the growth of HCT116, HCT-116 p53 $3^{-/}$and HCT-116 p $21^{-/}$cells. HCT-116, HCT-116 p53 ${ }^{-/}$and HCT-116 $\mathrm{p}^{-/-}$cells were seeded at $8 \times 10^{3}$ cells/well in 96-well microtiter plates. On the following day the cells were replenished with medium containing $0.1 \%$ DMSO or $1,2,3,4$, or $5 \mu \mathrm{M}$ DPD. Cells were treated for $48 \mathrm{~h}$ and analyzed by Sulforhodamine (SRB) binding assay. Each determination represents mean \pm SD absorbance of three replicates. The data are representative of three reproducible independent experiments.

The growth of HCT-116 wild-type cells was much more sensitive to DPD treatment than $\mathrm{p} 53^{-/}$or $\mathrm{p} 21^{-/}$cells.

Effects of DPD on cell cycle progression and cell signaling proteins expression in HCT-116, HCT-116 $\mathrm{p5}^{-1-}$ and HCT-116 $p 21^{-/}$cells. We also investigated the effect of DPD on cell cycle progression of HCT-116 human colon cancer cells with different p53 or p21 genetic backgrounds. The cell cycle progression of HCT-116 p53/- and HCT-116 p21/- cells were similar in the absence of DPD treatment (Fig. 4A). However, DPD treatment increased the percentage of $\mathrm{G}_{0} / \mathrm{G}_{1}$ phase ( 88.67 vs. $\left.49.02 \%\right)$ cells and reduced the cells in the S (3.22 vs. $34.86 \%)$ and $\mathrm{G}_{2} \mathrm{M}(8.1$ vs. $16.12 \%)$ phases. In contrast, such effect was not observed in HCT-116 p53 $3^{--}$and HCT-116 p $21^{-/-}$cells. Western blot analyses of $\mathrm{pRb}$, cyclin $\mathrm{D} / \mathrm{CDK} 4$ and cyclin $\mathrm{E} / \mathrm{CDK} 2$ in both DPD treated-HCT-116 $\mathrm{p} 53^{-/-}$and HCT-116 $\mathrm{p} 21^{-/}$cells revealed no significant difference as compared to wild-type HCT-116 cells (Fig. 4B).

Effects of DPD on cell migration of HCT-116, HCT-116 p53-1and HCT-116 p21- cells. To investigate the DPD effect on cell migration of colon cancer cells, we used the Transwell migra-
A

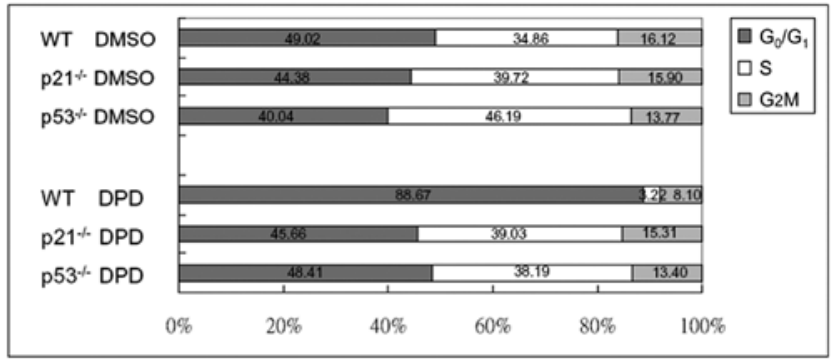

B
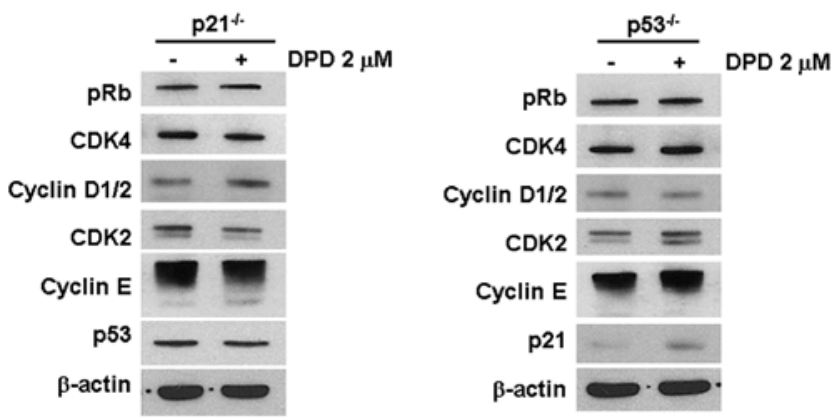

Figure 4. (A) Effects of DPD on cell cycle progression of HCT-116, (WT) HCT-116 $\mathrm{p} 53^{-/}$and HCT-116 p $21^{-/}$cells. Cells were seeded at a density of $2 \times 10^{5}$ cells/well in 6-well plates and allowed to attach for $24 \mathrm{~h}$. The original culture medium then was changed to medium with $0.1 \%$ DMSO or $2 \mu \mathrm{M}$ DPD. Cells were harvested and processed for cell cycle analysis by flow cytometry after treatment for $48 \mathrm{~h}$. Experiments shown are representative of three independent experiments. (B) Cell cycle related protein expression in HCT-116, HCT-116 p53 $3^{-/}$and HCT-116 p21 $1^{-/}$cells after treatment for $48 \mathrm{~h}$. Whole cell lysates from HCT-116, HCT-116 p53 $3^{-/}$and HCT-116 p $21^{-/}$cells were used for gel electrophoresis and Western blotting with primary antibodies against $\mathrm{p} 21$, p53, pRb, cyclin D1/2, cyclin E, CDK4, CDK2 and $\beta$-actin.

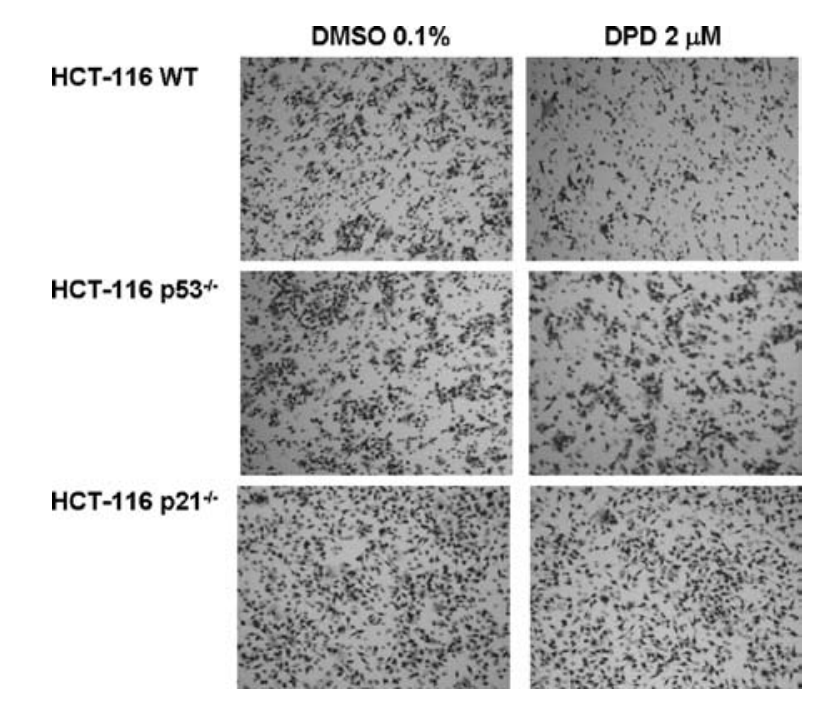

Figure 5. Effects of DPD on cell motility of HCT-116, HCT-116 $\mathrm{p} 53^{-/-}$and HCT-116 p $2^{1-\kappa}$ cells. HCT-116, HCT-116 p53 $3^{-/}$and HCT-116 p21 $1^{--}$cells were treated with $0.1 \%$ DMSO or $2 \mu \mathrm{M}$ DPD for $48 \mathrm{~h}$, then seeded at a density of $1 \times 10^{5}$ cells/well in 24-well Transwell plates and allowed to migrate for $24 \mathrm{~h}$. Each condition was assayed in triplicate and the results were reproducible.

tion assay. The motility was decreased in DPD treated-HCT-116 and HCT-116 $\mathrm{p}^{-/} 3^{-}$cells, but no significant effect was found on the migration of DPD treated-HCT-116 $\mathrm{p} 21^{-/}$cells (Fig. 5). 
A

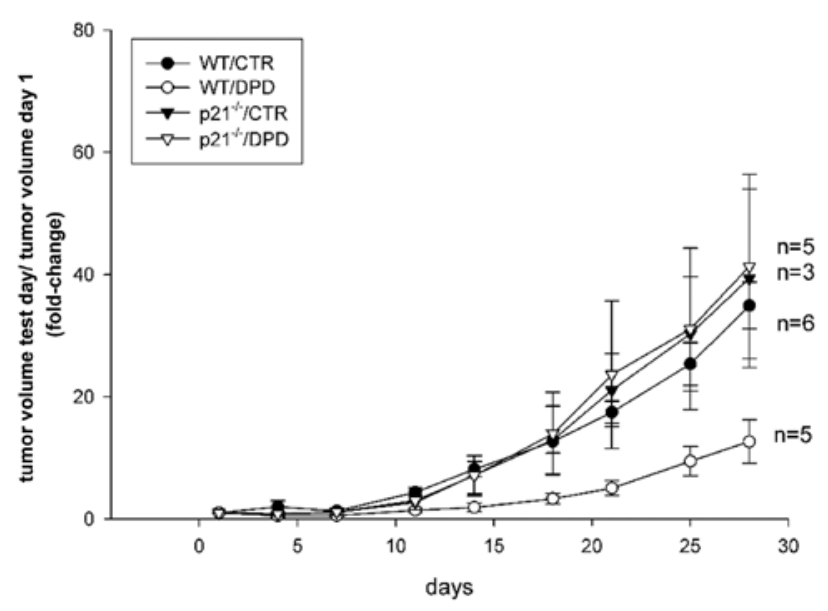

B

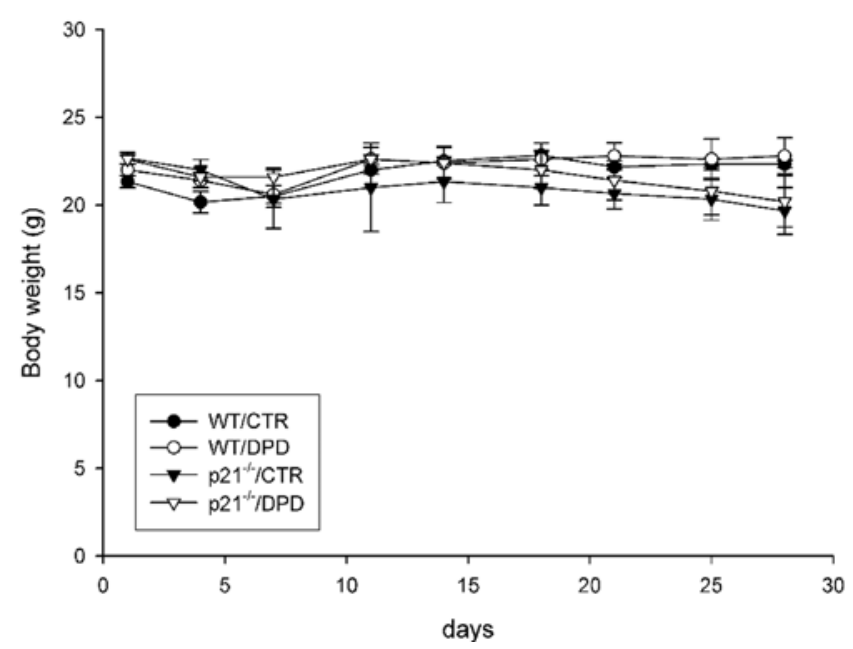

Figure 6. (A) In vivo anti-proliferative effect of DPD for human colon cancer HCT-116 and HCT-116 p21 ${ }^{-/}$xenografts. Each data are the mean \pm SE, calculated from the ratio of tumor volume on the test day to that on day 1 , from 3-6 samples of one representative experiment. The tumor growth index was significantly decreased in mice treated with DPD compared to control group in HCT-116 xenograft mice model $(\mathrm{P}<0.05)$. (B) Change in body weight of nude mice after treatment with DPD. Each data are the mean \pm SE from 3-6 samples of one representative experiment.

In vivo anti-proliferative effect of DPD in human colon cancer HCT-116 and HCT-116 p21-- xenografts. The HCT-116 and HCT-116 p21 ${ }^{--}$tumor bearing nude mice showed similar tumor indices at the end of the experiments. After treatment of tumor bearing nude mice with DPD, the tumor index was significantly decreased in DPD treated HCT-116 mice as compared to that of the control group but no tumor growth inhibition was observed in the HCT-116 p21 $1^{-/}$xenograft group (Fig. 6A). No significant reduction in body weight was found in DPD-treated mice (Fig. 6B).

\section{Discussion}

It is well known that cell cycle arrest can occur by loss of CDK activity and the inactivation of CDKs by CDKIs (cyclin-CDK inhibitor) including p16, p21, and p27 (13). It has been reported that mevastatin inhibits cell growth through inhibition of the cyclin E/CDK2 activation and that p21 was not required in prostate cancer cells (17). Similar to mevastatin and a celecoxib analogue $(18,19)$, DPD-treated HCT-116 cells were arrested at the $\mathrm{G}_{1} / \mathrm{S}$ transition and showed increased cellular levels of p21 but not of cyclin E/CDK2 (Fig. 2). The CDKI, p21 acts at the checkpoint in the cell cycle at the $\mathrm{G}_{1}$ phase. DPD induced $\mathrm{G}_{0} / \mathrm{G}_{1}$ arrest through induction of $\mathrm{p} 21$ and inhibited the downstream proteins such as cyclin D/CDK4 and phosphorylation of Rb (Figs. 1 and 2). The hypophosphorylated Rb protein is increased in the $G_{1}$ arrest phase (20) and the decrease of cyclin $\mathrm{D}$ induces a switch between proliferation and differentiation (21). These results together suggest that DPD inhibits cell proliferation through the cyclin D/CDK4-p21 pathway and inhibits $\mathrm{pRb}$ expression in HCT-116 cells. These results were further confirmed by the experiments using genetically impaired HCT-116 cells. HCT-116 p53/- and HCT-116 p21/cells lost both the growth-inhibitory effect and $\mathrm{G}_{0} / \mathrm{G}_{1}$ arrest pattern of the cell cycle after DPD treatment.

Previous studies have also shown the p21 induction and $\mathrm{G}_{1}$ arrest by a $\mathrm{p} 53$-independent pathway (22) and the p21 involvement in cell growth and cell cycle of HCT-116 cells (23-25). It has been suggested that DPD induces p21 expression through a p53-independent pathway in colon cancer cells. p21 inhibited cell migration (26) and the metastatic progression of cancer (27). Moreover, p21 activation suppressed the cancer cell migration via a p53-independent mechanism (28). Treatments with DPD significantly decreased the cell migration in HCT-116 cells. These anti-migration and anticancer effects were abolished in HCT-116 p $21^{-/}$cells. Our functional studies identified that DPD inhibits cancer cell migration and tumor growth through p21 activation by a p53-independent pathway. These results were consistent with other reports and support the notion that $\mathrm{p} 21$ has a crucial role in anticancer therapy $(29,30)$.

We demonstrated that DPD treatment resulted in proliferation inhibition in HCT-116 cells, but not in HCT-116 p21 ${ }^{-/-}$cells by in vitro and in vivo experiments. p21 played a major role in DPD-induced anticancer activity. The p21 or p53-deficient colon cancer cells continued to proliferate in the presence of DPD. Therefore, although p21 or p53 was required for the growth inhibition and $\mathrm{G}_{0} / \mathrm{G}_{1}$ arrest, the anti-migration effect of DPD on HCT-116 was p53-independent. Our results suggest the anticancer defect of DPD through down-regulation of cyclin $\mathrm{D} / \mathrm{CDK} 4$ and $\mathrm{pRb}$, and up-regulation of p21 by a p53-independent mechanism. More investigations are needed to further define the detailed molecular mechanisms of the anticancer effects of DPD which will provide an innovative experimental framework to study the control of colon cancer cell progression.

\section{Acknowledgements}

The authors thank Dr Jing-Jer Lin (Professor of the National

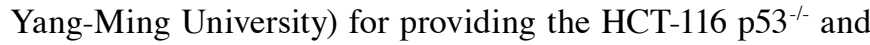
HCT-116 p21 ${ }^{-/}$cells used in these experiments. This study was supported by the NSC 97-2320-B-227-001-MY3 grant and in part by a grant from the Taipei Veterans General Hospital (VGH V99C1-053) and the Department of Health (DOH99TD-C-111-007), Taiwan. 


\section{References}

1. Giovannucci E: Modifiable risk factors for colon cancer Gastroenterol Clin North Am 31: 925-943, 2002.

2. Jemal A, Bray F, Center MM, Ferlay J, Ward E and Forman D: Global cancer statistics. CA Cancer J Clin 61: 69-90, 2011.

3. Saltz LB, Cox JV, Blanke C, et al: Irinotecan plus fluorouracil and leucovorin for metastatic colorectal cancer. Irinotecan Study Group. N Engl J Med 343: 905-914, 2000.

4. Goldberg RM, Sargent DJ, Morton RF, et al: A randomized controlled trial of fluorouracil plus leucovorin, irinotecan, and oxaliplatin combinations in patients with previously untreated metastatic colorectal cancer. J Clin Oncol 22: 23-30, 2004.

5. Cunningham D, Atkin W, Lenz HJ, et al: Colorectal cancer. Lancet 375: 1030-1047, 2010.

6. Hecht JR: Gastrointestinal toxicity or irinotecan. Oncology (Williston Park) 12: 72-78, 1998

7. Gamelin E, Gamelin L, Bossi L and Quasthoff S: Clinical aspects and molecular basis of oxaliplatin neurotoxicity: current management and development of preventive measures. Semin Oncol 29: 21-33, 2002.

8. Aigami K, Inamoto Y, Takaishi N, Hattori K and Takatsuki A: Biologically active polycycloalkanes. 1. Antiviral adamantane derivatives. J Med Chem 18: 713-721, 1975.

9. Wang JJ, Wang SS, Lee CF, Chung MA and Chern YT: In vitro antitumor and antimicrobial activities of $\mathrm{N}$-substituents of maleimide by adamantane and diamantane. Chemotherapy 43 : $182-189,1997$.

10. Wang JJ, Chern YT, Liu TY and Chi CW: In vitro and in vivo growth inhibition of cancer cells by adamantylmaleimide derivatives. Anticancer Drug Des 13: 779-796, 1998.

11. Wang JJ, Huang KT and Chern YT: Induction of growth inhibition and G1 arrest in human cancer cell lines by relatively low-toxic diamantane derivatives. Anticancer Drugs 15: 277-286, 2004.

12. Wang JJ, Chang YF, Chern YT and Chi CW: Study of in vitro and in vivo effects of 1,6-Bis[4-(4-amino-3-hydroxyphenoxy) phenyl]diamantane (DPD), a novel cytostatic and differentiation inducing agent, on human colon cancer cells. Br J Cancer 89: 1995-2003, 2003.

13. Sherr CJ and Roberts JM: CDK inhibitors: positive and negative regulators of G1-phase progression. Genes Dev 13: 1501-1512, 1999.

14. Pasz-Walczak G, Kordek R and Faflik M: P21 (WAF1) expression in colorectal cancer: correlation with P53 and cyclin D1 expression, clinicopathological parameters and prognosis. Patho Res Pract 197: 683-689, 2001.

15. Han Z, Wei W, Dunaway S, et al: Role of p21 in apoptosis and senescence of human colon cancer cells treated with camptothecin. J Biol Chem 277: 17154-17160, 2002.

16. Workman P, Twentyman P, Balkwill F, et al: United Kingdom Co-ordinating Committee on Cancer Research (UKCCCR) Guidelines for the Welfare of Animals in Experimental Neoplasia (Second Edition). Br J Cancer 77: 1-10, 1998.
17. Ukomadu $\mathrm{C}$ and Dutta $\mathrm{A}$ : Inhibition of cdk2 activating phosphorylation by mevastatin. J Biol Chem 278: 4840-4846, 2003.

18. Ukomadu C and Dutta A: p21-dependent inhibition of colon cancer cell growth by mevastatin is independent of inhibition of G1 cyclin-dependent kinases. J Biol Chem 278: 43586-43594, 2003.

19. Lee E, Choi MK, Han IO and Lim SJ: Role of p21CIP1 as a determinant of SC-560 response in human HCT116 colon carcinoma cells. Exp Mol Med 38: 325-331, 2006.

20. Yen A and Sturgill R: Hypophosphorylation of the RB protein in S and G2 as well as G1 during growth arrest. Exp Cell Res 241: 324-331, 1998.

21. Gillett CE and Barnes DM: Demystified ... cell cycle. Mol Pathol 51: 310-316, 1998.

22. Jeong JH, Kang SS, Park KK, Chang HW, Magae J and Chang YC: p53-independent induction of G1 arrest and p21WAF1/CIP1 expression by ascofuranone, an isoprenoid antibiotic, through downregulation of c-Myc. Mol Cancer Ther 9: 2102-2113, 2010.

23. Bataller M, Mendez C, Salas JA and Portugal J: Cellular response and activation of apoptosis by mithramycin SK in p21(WAF1)deficient HCT116 human colon carcinoma cells. Cancer Lett 292: 80-90, 2010.

24. Hata T, Yamamoto H, Ngan CY, et al: Role of p21waf1/cip1 in effects of oxaliplatin in colorectal cancer cells. Mol Cancer Ther 4: 1585-1594, 2005.

25. Hemmati PG, Normand G, Gillissen B, Wendt J, Dorken B and Daniel PT: Cooperative effect of p21Cip1/WAF-1 and 14-33 sigma on cell cycle arrest and apoptosis induction by p14ARF. Oncogene 27: 6707-6719, 2008.

26. Fukui R, Shibata N, Kohbayashi E, et al: Inhibition of smooth muscle cell migration by the p21 cyclin-dependent kinase inhibitor (Cip1). Atherosclerosis 132: 53-59, 1997.

27. Engelman RW, Jackson RJ, Coppola D, Wharton W, Cantor AB and Pledger WJ: Loss of nuclear p21(Cip1/WAF1) during neoplastic progression to metastasis in gamma-irradiated $\mathrm{p} 21$ hemizygous mice. Exp Mol Pathol 82: 234-244, 2007.

28. Kovacevic Z, Sivagurunathan S, Mangs H, Chikhani S, Zhang D and Richardson DR: The metastasis suppressor, $\mathrm{N}$-myc downstream regulated gene 1 (NDRG1), upregulates p21 via p53-independent mechanisms. Carcinogenesis 32: 732-740, 2011.

29. Motwani M, Jung C, Sirotnak FM, et al: Augmentation of apoptosis and tumor regression by flavopiridol in the presence of CPT-11 in Hct116 colon cancer monolayers and xenografts. Clin Cancer Res 7: 4209-4219, 2001.

30. Lazzarini R, Moretti S, Orecchia S, Betta PG, Procopio A and Catalano A: Enhanced antitumor therapy by inhibition of p21waf1 in human malignant mesothelioma. Clin Cancer Res 14: 5099-5107, 2008.

31. Attia MA and Weiss DW: Immunology of spontaneous mammary carcinomas in mice. V. Acquired tumor resistance and enhancement in strain A mice infected with mammary tumor virus. Cancer Res 26: 1787-1800, 1966. 